International Journal of

Health, Medicine and

Nursing Practice

(IJHMNP)

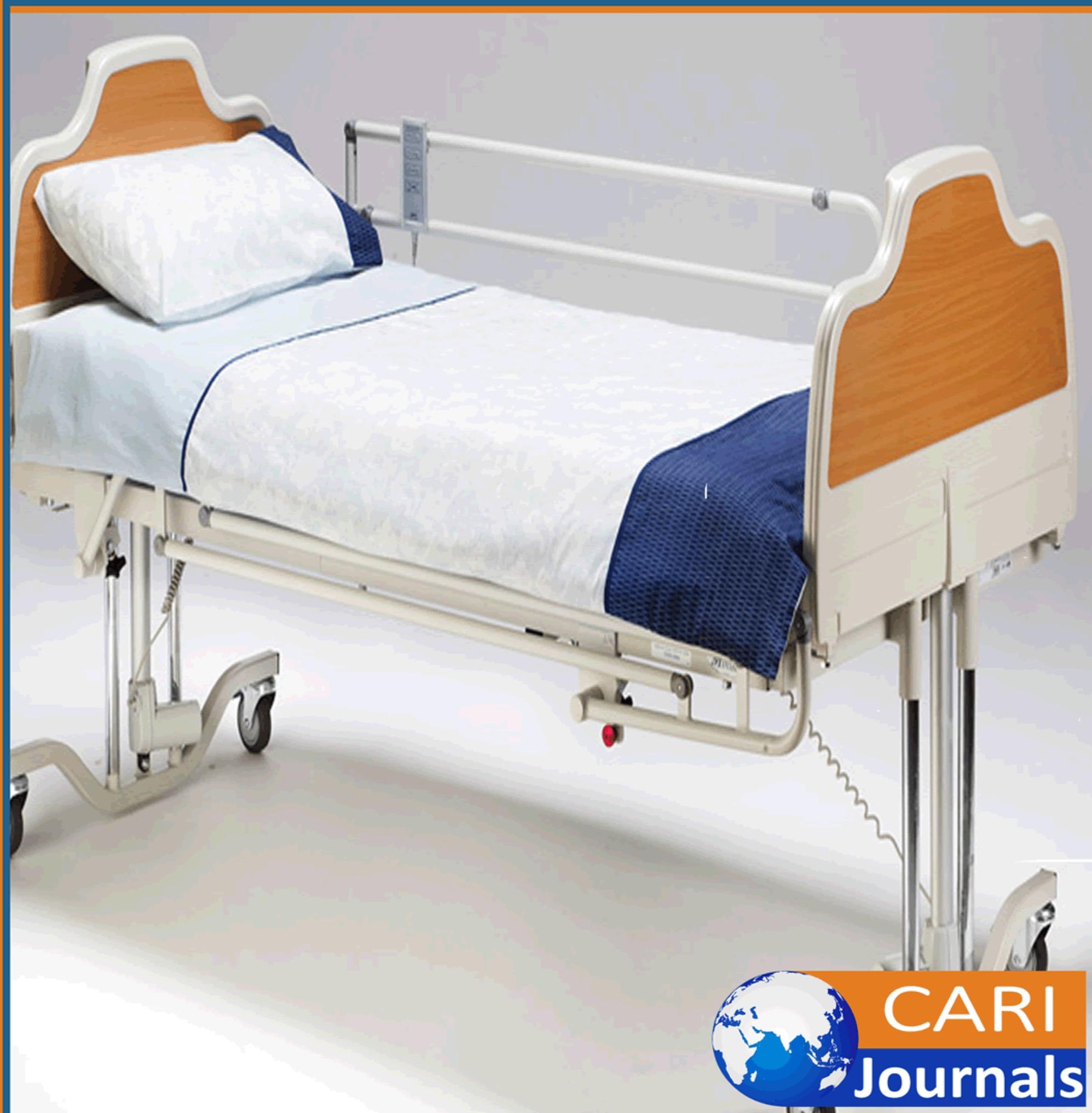




\title{
Adherence to Cold-Chain Management Guidelines and Influence on Stability of Live Attenuated Vaccines: Results from an Observational Study in Kisumu County, Kenya.
}

\author{
$1 *$ Moses Olunga Okomo John \\ Post Graduate student: School of Public Health and Community Development \\ Department of Public Health, \\ P. O. Box $333-40105$ \\ Maseno, Kenya \\ Mobile +254-720847278/753335777 \\ *Corresponding Author's Email: jomokomo2010@yahoo.com \\ ${ }^{2}$ Dickens S. Omondi Aduda, $\mathrm{PhD}$;
}

\section{Lecturer}

School of Health Sciences / Centre for Research, Innovation and Technology (CRIT), Jaramogi Oginga Odinga University of Science and Technology, Kenya

Email: omondisda@gmail.com

${ }^{3}$ Bernard Guyah $\mathrm{PhD}$

\section{Lecturer}

School of Public Health and Community Development, Department of Biomedical Sciences and Technology,

Maseno University, Kenya

Email: guyah.benard@yahoo.com

\begin{abstract}
Purpose: Guidelines provide ethical frameworks to streamline processes for best outcomes. Liveattenuated vaccines in routine immunization programs in Kenya have challenges of instability despite the availability of guidelines. Diseases preventable by these vaccines are reported in Kisumu County more than others in the region. This observation is suspected to be associated with lapses in adherence to cold-chain management procedures. This study, hence purposed to assess whether there was any association between instability of vaccines and staff adherence level to the guidelines.

Method: Using analytical cross-sectional design with repeated observations, data was collected from 120 out of 170 public and non-governmental health facilities in the Kisumu County at three intervals, between October 2018 and March 2019. In each health facility, immunization manager on duty was
\end{abstract}


interviewed and observations made on compliance with cold-chain protocols using a checklist. Data was summarized descriptively and regression used to identify key points of adherence levels. Qualitative information was analyzed thematically to identify evolving themes.

Result: In $40 \%$ of the facilities, staff did not transfer vaccines when the need arose; $8.3 \%$ did not defrost fridges; while $45.8 \%$ did not dispense vaccines at VVM stage 2. Transferred vaccines accounted for improved stability of both OPV (95\%C.I; $3.1-16.8$, OR 7.2, p value< 0.001) and measles-rubella vaccines (95\% C.I, $2.1-10.4$, OR, 4.7, $\mathrm{p}=$ value $<0.001)$. Dispensing vaccines at VVM stage 2 ahead of FEFO had better stability of OPV (95\%C.I, 6.0 - 49, OR17.2, p=value <0.001) and measles-rubella vaccines (95\%C.I 3.3-17.4; OR7.6, $\mathrm{p}=$ value <0.001) respectively. Defrosted fridge enhanced stability of OPV (95\% C.I, 1.1 - 15.5; OR 4.17, p=value 0.033), measles-rubella (95\% C.I, 1.3 - 12.3, OR 4, p-value 0.0017) and ROTA vaccine (95\% C.I 1.9 - 21.5; OR 6.3, p= value 0.003).

Unique contribution to practice and policy: Lapses in transferring vaccines, defrosting of fridges and use of VVM to dispense vaccines significantly destabilized live attenuated vaccines worth linking to the outbreaks of Rota diarrhea and measles outbreaks in Kisumu. Due to inadequate staff adherence level to guidelines, new innovations meant to help improve stability of vaccines, inadequately improved the situation, so calls for strengthened capacity building to staff.

Key words: Cold-chain system; adherence; guidelines; vaccine stability; routine immunization;

\section{BACKGROUND}

Stable vaccines contribute significantly in the promotion of good health indicators among children below five years worldwide (MoH 2012; Angela et al., 2014, WHO 2015a, Okomo et al., 2019). Loss of vaccine stability due to any lapses has a considerable adverse impact on the success of immunization program. Vaccines stability refers to their ability to retain physical, chemical, biological, biopharmaceutical and microbiological properties within specified limits to assure clinical performance throughout shelf-life (Shen, et al., 2014). This is detectable in clinical set ups through the use of Vaccine vial monitor (VVM) gadgets which are attached to each vaccine vial. Both adverse heat events (occurring when vaccines experience temperatures $\geq 8^{\circ} \mathrm{C}$ for over 10 hours) and adverse cold events (occurring when vaccines experience temperatures $\leq-5^{\circ} \mathrm{C}$ for at least one hour) lead to degradation of vaccines immunological properties, consequently compromising their protective efficacy to the individuals receiving them. Adherence to cold-chain management guidelines is critical in improving time vaccines spend within the correct range thus sustaining their stability (WHO 2006, 2015a, 2015b). In Kenya, the national vaccines and immunization program manages the cold-chain system to ensure that all eligible children receive safe quality vaccines. The recent introduction of remote temperature monitoring technology besides fridge tag2 to monitor vaccine fridges provides an important additional tool to enable health managers to detect and address recurring lapses promptly hence, enhancing coldchain management throughout the vaccine supply system (Lutukai, et al., 2019, Okomo et al., 2019). However, recent evidence from facility national surveys indicates that maintaining cold-chain systems at the service delivery points remain a major challenge despite availability of cold-chain infrastructure and operational guidelines (MoH, 2012; Lutukai, 2019). In contrast, mass immunization campaigns, especially for Polio and Measles, gives relatively a better disease control results than routine immunization process due to higher efficiency and conscientious adherence to cold-chain management 
guidelines (MoPHS 2013; Okomo et al., 2019). This variance indicates potential lapses or less rigor in cold-chain management during routine immunization services.

To ensure quality of vaccines, immunization services staff providers are expected to perform the following procedures to sustain optimal vaccine quality. They are expected to: place diluents for use in fridges or carriers before use; place reserve icepacks in an alternative carrier during outreach; arrange vaccines in fridge based on their sensitivity levels to heat and cold. They are also expected to defrost fridges in time; chart temperature twice a day; transfer vaccines when a fridge is faulty; dispense any vaccine at VVM stage 2 ahead of FEFO sequence; accurately interpret VVM stages and observe FEFO sequence. Whereas guidelines and job aids are available per facility to guide practice by immunization providers and managers, their level of adherence remains unclear, despite regular support supervision.

In Kisumu County DHIS- Kenya 2014, 2015 and 2016 reports show progressive improved vaccination coverage from below $70 \%$ to $90 \%$ over the period, but with occasional upsurges of measles, Rota diarrhoea and tuberculosis, very inconsistent with the coverage levels. Fridge tag 2 records of aberrant temperature excursions beyond the recommended temperature range of between $2^{\circ} \mathrm{C}-8^{\circ} \mathrm{C}$ indicate lapses in cold-chain management system largely attributable to staff errors. The current study aimed to assess staff adherence levels to routine cold-chain management guidelines and determine potential influence of this on the stability of live attenuated vaccines at health facilities in Kisumu County. The findings are valuable to policy makers, service delivery managers and providers to enable them to develop targeted quality improvement interventions for respective contexts.

\section{METHODOLOGY}

\section{Design and Sampling Procedure}

The study was set and conducted in all sub-Counties of Kisumu, using an analytical cross-sectional design with repeated observations. The sample frame comprised of all health workers deployed to handle vaccines at 170 health facilities. These units were further categorized according to level of care (level 2 or 3 and above); and type of ownership (public or private). A sample of 120 facilities was calculated based on the Yamane (1967) simplified formula. Study facilities were identified per strata using simple random sampling as shown in Tablelbelow. Data collection was done in three cycles of two Months interval using a pre-tested checklist adapted from WHO guidelines. A measure of reliability was performed on the three cycles of data as stated by Cronbach's alpha in (Gliem et.al. 2003). The second cycle reported the highest alpha of 0.8093 , so was treated as most reliable, followed by first batch with an alpha of 0.7903 while third had an alpha of 0.7330 . In each facility, immunization manager on duty on the day of study visit were identified as per the duty rosters. They were interviewed to ascertain their level of adherence to the guideline and influence on stability of live attenuated vaccines. Observation on their actual practice was also made. Reports of fridge tag two gadgets and those of VVMs' color code changes, guided the determination of the level of adherence to the guidelines and stability levels of vaccines in each facility. 
International Journal of Health, Medicine and Nursing Practice

ISSN 2520- 0852 (Online)

Vol, 2, Issue No, 1. Pp 1-13, 2020

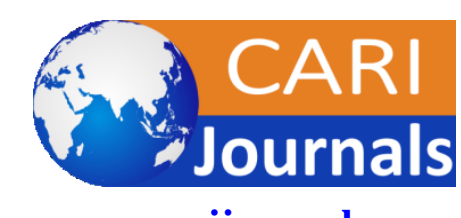

www.carijournals.org

Table 1: Sample size and sampling procedure

\begin{tabular}{|c|c|c|c|c|c|c|}
\hline \multirow{3}{*}{ SUB COUNTY } & \multirow{3}{*}{$\begin{array}{c}\text { \# OF HEALTH } \\
\text { FACILITIES } \\
\text { AVAILABLE PER SUB- } \\
\text { COUNTY / \# SAMPLED }\end{array}$} & \multicolumn{2}{|c|}{$\begin{array}{l}\text { HEALTH FACILITY LEVEL } \\
\geq 3\end{array}$} & \multicolumn{2}{|c|}{$\begin{array}{l}\text { HEALTH FACILITY LEVEL } \\
2\end{array}$} & \multirow[t]{3}{*}{ TOTALS: } \\
\hline & & \multicolumn{2}{|c|}{ OWNERSHIP } & \multicolumn{2}{|c|}{ OWNERSHIP } & \\
\hline & & GOK & FB / PR & GOK & FB / PR & \\
\hline \multirow[t]{2}{*}{ KISUMU EAST } & \# H/FACILITIES & 9 & 13 & 14 & 11 & 47 \\
\hline & \# SAMPLED & 6 & 9 & 10 & 8 & 33 \\
\hline \multirow[t]{2}{*}{ KISUMU WEST } & \# H/FACILITIES & 3 & 4 & 13 & 3 & 23 \\
\hline & \#SAMPLED & 2 & 3 & 9 & 2 & 16 \\
\hline \multirow[t]{2}{*}{ MUHORONI } & \# H/FACILITIES & 3 & 2 & 18 & 8 & 31 \\
\hline & \#SAMPLED & 2 & 1 & 13 & 6 & 22 \\
\hline \multirow[t]{2}{*}{ SEME } & \# H/FACILITIES & 3 & $\mathbf{0}$ & 21 & 1 & 25 \\
\hline & \#SAMPLED & 2 & 0 & 15 & 1 & 18 \\
\hline \multirow[t]{2}{*}{ NYANDO } & POPULATION & 3 & 3 & 14 & & 20 \\
\hline & SAMPLE & 2 & 2 & 10 & 0 & 14 \\
\hline \multirow[t]{2}{*}{ NYAKATCH } & POPULATION & 4 & 4 & 13 & 3 & 24 \\
\hline & SAMPLE & 3 & 3 & 9 & 2 & 17 \\
\hline \multirow[t]{2}{*}{ TOTAL } & POPULATION & 25 & 26 & 93 & 26 & 170 \\
\hline & SAMPLE & 17 & 18 & 66 & 19 & 120 \\
\hline
\end{tabular}

GOK (Government of Kenya) - Public Health facilities; FB_ Faith Based health facilities / PR-Private Health facilities

\section{Data Analysis}

Using SPSS version 20, data were summarized descriptively. Frequency distribution tables for both stability statuses of each vaccine and adherence levels of staff with the guidelines are reported. The levels of vaccine stability were clustered into "stable" and "unstable"; this allowed the use of generalized estimating equation algorithm customized for logistic regression with a binomial link. Chisquare inferential test was performed to detect the association between the two variables. Fisher's exact test was used whenever some cell values were either 0 or below 5. Bivariate and multivariate regression analyses were performed to identify factors that might be associated with instability of liveattenuated vaccines. Odds ratios and confidence intervals were then reported. Qualitative information was coded and analyzed thematically to identify evolving themes on staff practice and attitude.

\section{Limitations}

The method was limited to assessing how staff attitudes and adherence levels to cold-chain management's guidelines influence stability of live-attenuated vaccines at health facilities in the County, through the guidance of vaccine vial monitors and fridge tag2. Laboratory titter was not performed.

\section{RESULTS}

\section{Variable characteristics of e study participants}


The study comprised of 120 participants from the six sub-Counties, representing $70 \%$ of health facilities. The majority of service providers were nurses $(98.3 \% ; n=118)$ and $1.7 \%(n=2)$ public health officers. Of these, $73.3 \%(\mathrm{n}=88)$ were females, whereas males were $26.7 \%(\mathrm{n}=32)$. The majority of participants, $89.2 \%(n=107)$ had 2 years or more of experience. Most of the staff were aged between 36-60 years with a frequency of $63.3 \%(n=76)$ followed by 20-35 years, $31.7 \%(n=38)$ and finally those above 60 years were $5 \%(n=6)$. In terms of facility type and ownership, there were $66.7 \%(n=80)$ public facilities, 33.3\% $(\mathrm{n}=40)$ private facilities including faith based. As for the level of operation, $70 \%(n=84)$ were level two while $30 \%(n=36)$ were level 3 and above. (See table 2)

Table 2: Summary Statistics of Personal Characteristics and Facility information

\begin{tabular}{|c|c|c|c|}
\hline Characteristic & Frequency $(\%)$ & Lower $95 \%$ CI & Upper $95 \%$ CI \\
\hline \multicolumn{4}{|l|}{ Designation } \\
\hline Nurse & $98.33(n=118)$ & 93.46 & 99.59 \\
\hline PHO & $(1.67 \%(n=2)$ & 4.09 & 6.54 \\
\hline \multicolumn{4}{|l|}{ Gender } \\
\hline Male & $26.7 \%(\mathrm{n}=32)$ & 15.11 & 30.06 \\
\hline Female & $73.3 \%(n=88)$ & 69.94 & 84.89 \\
\hline \multicolumn{4}{|l|}{ Experience } \\
\hline Less than a year & $3.3 \%(n=4)$ & 0.41 & 6.59 \\
\hline 1 to 2 years & $7.5 \%(\mathrm{n}=9)$ & 11.73 & 25.69 \\
\hline 2 years and above & $89.2 \%(n=107)$ & 72.46 & 86.88 \\
\hline \multicolumn{4}{|l|}{ Age } \\
\hline $20-35$ & $31.7 \%(n=38)$ & 30.50 & 48.19 \\
\hline $36-60$ & $63.3 \%(n=76)$ & 41.77 & 59.87 \\
\hline $60+$ & $5 \%(n=6)$ & 5.82 & 17.18 \\
\hline \multicolumn{4}{|l|}{ Type of Facility } \\
\hline Public & $66.7 \%(n=80)$ & 59.36 & 76.12 \\
\hline Private & $33.3 \%(n=40)$ & 23.88 & 40.63 \\
\hline \multicolumn{4}{|l|}{ Facility Level } \\
\hline 2 or Below & $70 \%(\mathrm{n}=84)$ & 56.78 & 73.86 \\
\hline 3 and Above & $30 \%(n=36)$ & 26.14 & 43.21 \\
\hline
\end{tabular}

Staff Adherence level to Cold-Chain Management Guidelines and Influence on live attenuated Vaccines Stability

In $40 \%$ of the health facilities, staff did not transfer vaccines when the need arose; $8.3 \%$ did not defrost fridges; while facilities that did not dispense vaccines at VVM stage 2 but FEFO sequences were 45.8\%. Transferred vaccines accounted for improved stability of both OPV (95\%C.I; 3.1 - 16.8, OR 7.2, p value $<0.001)$ and stable measles-rubella vaccine (95\% C.I, $2.1-10.4$, OR, 4.7, p=value $<0.001)$. In facilities that dispensed vaccines at VVM stage 2 ahead of FEFO sequences, OPV and measles-rubella vaccines were more stable (95\%C.I, 6.0 - 49, OR17.2, p=value <0.001) and (95\%C.I 3.325 -17.374; OR7.6, p=value <0.001) respectively. While defrosted fridges had enhanced stable 
International Journal of Health, Medicine and Nursing Practice ISSN 2520- 0852 (Online)

Vol, 2, Issue No, 1. Pp 1-13, 2020

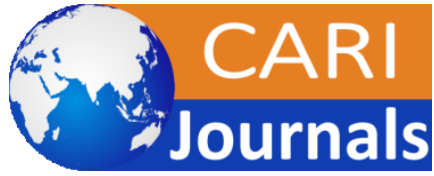

www.carijournals.org

OPV (95\% C.I, 1.1 - 15.5; OR 4.17, p=value 0.033), stable measles-rubella vaccines (95\% C.I, 1.3 12.3, OR 4, p-value 0.0017) and stable ROTA vaccine (95\% C.I $1.9-21.5$; OR 6.3, p= value 0.003). Arrangement of vaccines in the fridge had significant influence on the stability of OPV (p-value 0.030) but did not predict any vaccine stability (See table 3 and 4 ) below. Food staff and non EPI drugs were occasionally observed in some fridges

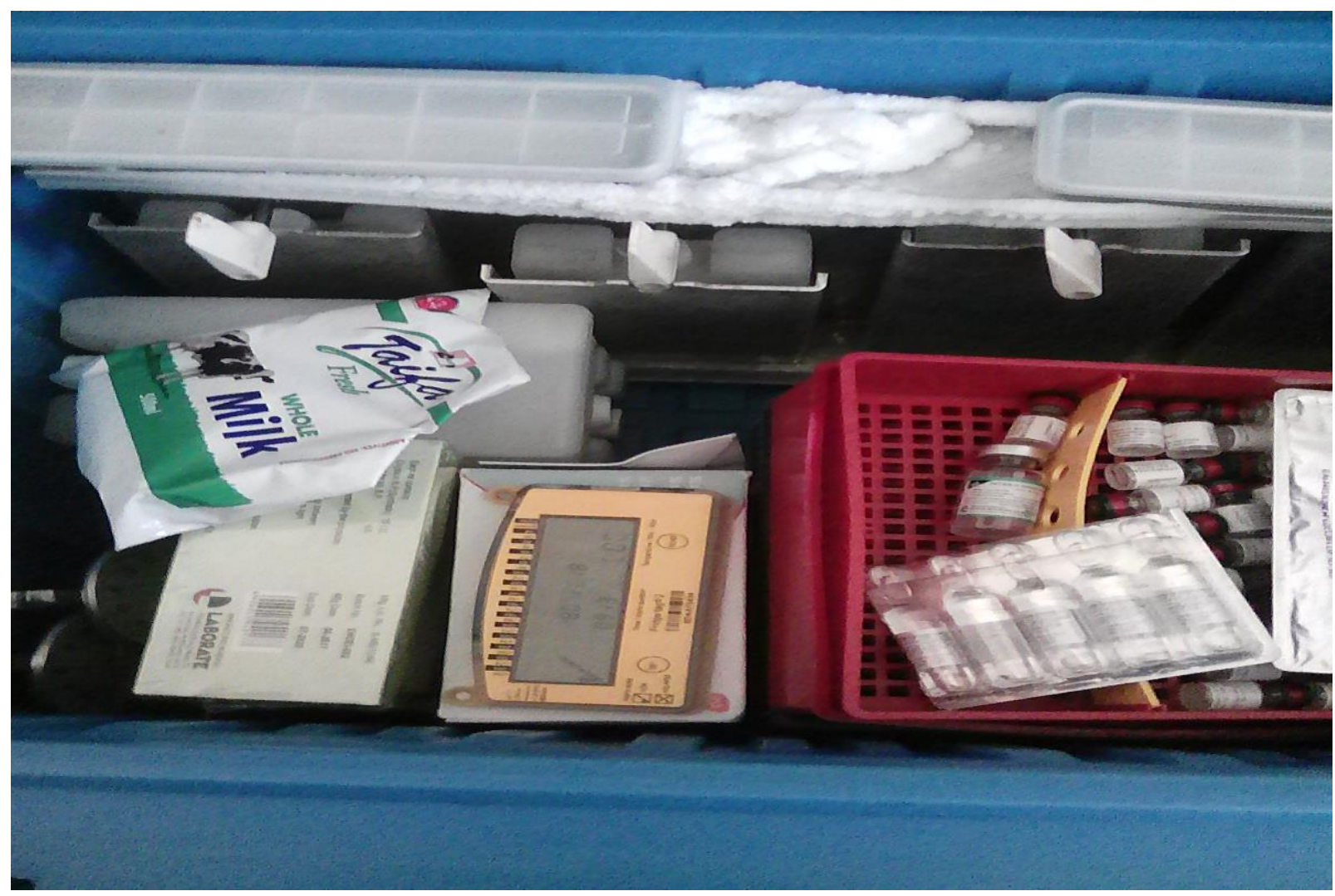

Figure 1: Food stuff and non EPI drugs placed in the Fridge

Table 3: Cold-chain's guidelines adherence levels

\begin{tabular}{llllc}
\hline POLICY FACTOR & YES & $\begin{array}{l}\text { PERCENT } \\
(\%)\end{array}$ & NO & $\begin{array}{c}\text { PERCENT } \\
(\%)\end{array}$ \\
\hline Diluents In Fridge / Carrier & 104 & $86.7 \%$ & 16 & $13.3 \%$ \\
Extra Icepacks In Carrier & 4 & $28.6 \%$ & 10 & $71.4 \%$ \\
Vaccines Arrangement As Per Policy & 81 & $67.5 \%$ & 39 & $32.5 \%$ \\
Fridge Defrosted & 110 & $91.7 \%$ & 10 & $9.3 \%$ \\
Temperature Monitored Twice & 75 & $62.5 \%$ & 45 & $37.5 \%$ \\
Manual Temperature March Ft2 & 48 & $40 \%$ & 72 & $60 \%$ \\
Vaccines Transferred As Per Need & 74 & $61.7 \%$ & 46 & $38.3 \%$
\end{tabular}


International Journal of Health, Medicine and Nursing Practice ISSN 2520- 0852 (Online)

Vol, 2, Issue No, 1. Pp 1-13, 2020

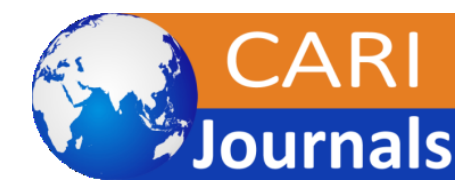

www.carijournals.org

\begin{tabular}{llllc} 
VVM Stage 2 Issued Before FEFO & 72 & $60 \%$ & 55 & $40 \%$ \\
VVM Accurately Recorded & 70 & $58.3 \%$ & 50 & $41.7 \%$ \\
\hline
\end{tabular}

Table 4: Bivariate and multivariate analysis of providers' adherence levels to guidelines and stability of vaccines

\begin{tabular}{|c|c|c|c|c|}
\hline \multirow[b]{2}{*}{ Factor } & \multicolumn{4}{|c|}{ Bivariate Logistic Analysis of OPV } \\
\hline & Odds Ratio & p-value & & \\
\hline \multicolumn{5}{|c|}{ FRIDGE DEFROST } \\
\hline YES & 4.17 & $0.033^{*}$ & 1.122 & 15.499 \\
\hline NO & Ref & Ref & Ref & Ref. \\
\hline \multicolumn{5}{|c|}{ VACCINES ARRANGED PER POLICY } \\
\hline YES & 3.036 & $0.106^{*}$ & 0.791 & 11.65 \\
\hline $\mathrm{NO}$ & Ref & Ref & Ref & Ref. \\
\hline \multicolumn{5}{|c|}{ VACCINES TRANSFERRED } \\
\hline YES & 7.216 & $<0.001 *$ & 3.091 & 16.846 \\
\hline NO & Ref & Ref & Ref & Ref. \\
\hline \multicolumn{5}{|c|}{ VVM2 ISSUED BEFORE FIFO/FEFO } \\
\hline YES & 17.15 & $<0.001^{*}$ & 6.014 & 48.909 \\
\hline $\mathrm{NO}$ & Ref & Ref & Ref & Ref. \\
\hline \multicolumn{5}{|c|}{ Bivariate Logistic Analysis of $M / R$} \\
\hline Factor & Odds Ratio & & & \\
\hline \multicolumn{5}{|c|}{ FRIDGE DEFROSTED } \\
\hline YES & 3.984 & $0.017 *$ & 1.286 & 12.342 \\
\hline $\mathrm{NO}$ & Ref & Ref & Ref & Ref. \\
\hline \multicolumn{5}{|c|}{ VACCINES TRANSFERRED } \\
\hline YES & 4.741 & $<0.001 *$ & 2.163 & 10.392 \\
\hline $\mathrm{NO}$ & Ref & Ref & Ref & Ref. \\
\hline \multicolumn{5}{|c|}{ VVM2 ISSUED BEFORE FIFO/FEFO } \\
\hline YES & 7.600 & $<0.001 *$ & 3.325 & 17.374 \\
\hline NO & Ref & Ref & Ref & Ref. \\
\hline \multicolumn{5}{|c|}{ Multivariate Logistic Analysis of $M / R$} \\
\hline Factor & Odds Ratio & p-value & & \\
\hline \multicolumn{5}{|c|}{ VVM2 ISSUED BEFORE FIFO/FEFO } \\
\hline YES & 4.419 & $0.002 *$ & 1.708 & 11.433 \\
\hline $\mathrm{NO}$ & Ref & Ref & Ref & Ref. \\
\hline
\end{tabular}

Bivariate Logistic Analysis of ROTA 
International Journal of Health, Medicine and Nursing Practice

ISSN 2520- 0852 (Online)

Vol, 2, Issue No, 1. Pp 1-13, 2020

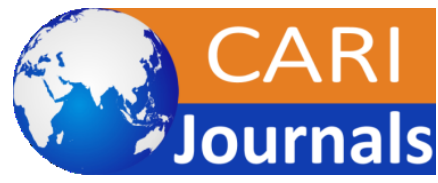

www.carijournals.org

\begin{tabular}{|c|c|c|c|c|}
\hline Factor & Odds Ratio & \multicolumn{2}{|c|}{ p-value } & $95 \% \mathrm{CI}$ \\
\hline \multicolumn{5}{|l|}{ FRIDGE DEFROST } \\
\hline YES & 6.333 & $0.003 *$ & 1.867 & 21.481 \\
\hline NO & Ref & Ref & Ref & Ref. \\
\hline \multicolumn{5}{|c|}{ VACCINES TRANSFERRED } \\
\hline YES & 4.469 & $0.015^{*}$ & 1.332 & 14.99 \\
\hline $\mathrm{NO}$ & Ref & Ref & Ref & Ref. \\
\hline \multicolumn{5}{|c|}{ Multivariate Logistic Analysis of ROTA } \\
\hline Factor & Odds Ratio & & & $95 \% \mathrm{CI}$ \\
\hline \multicolumn{5}{|l|}{ FRIDGE DEFROST } \\
\hline YES & 4.773 & $0.018 *$ & 1.307 & 17.438 \\
\hline NO & Ref & Ref & Ref & Ref. \\
\hline
\end{tabular}

Vaccines stability levels were classified into either stable or unstable. Findings revealed that $47 \%$ $(n=56)$ of the fridges had some unstable oral polio vaccines; $30 \%(n=36)$ had some unstable measlesrubella vaccines, and $15.8 \%(n=19)$ had some unstable ROTA vaccines. (See figure 1)

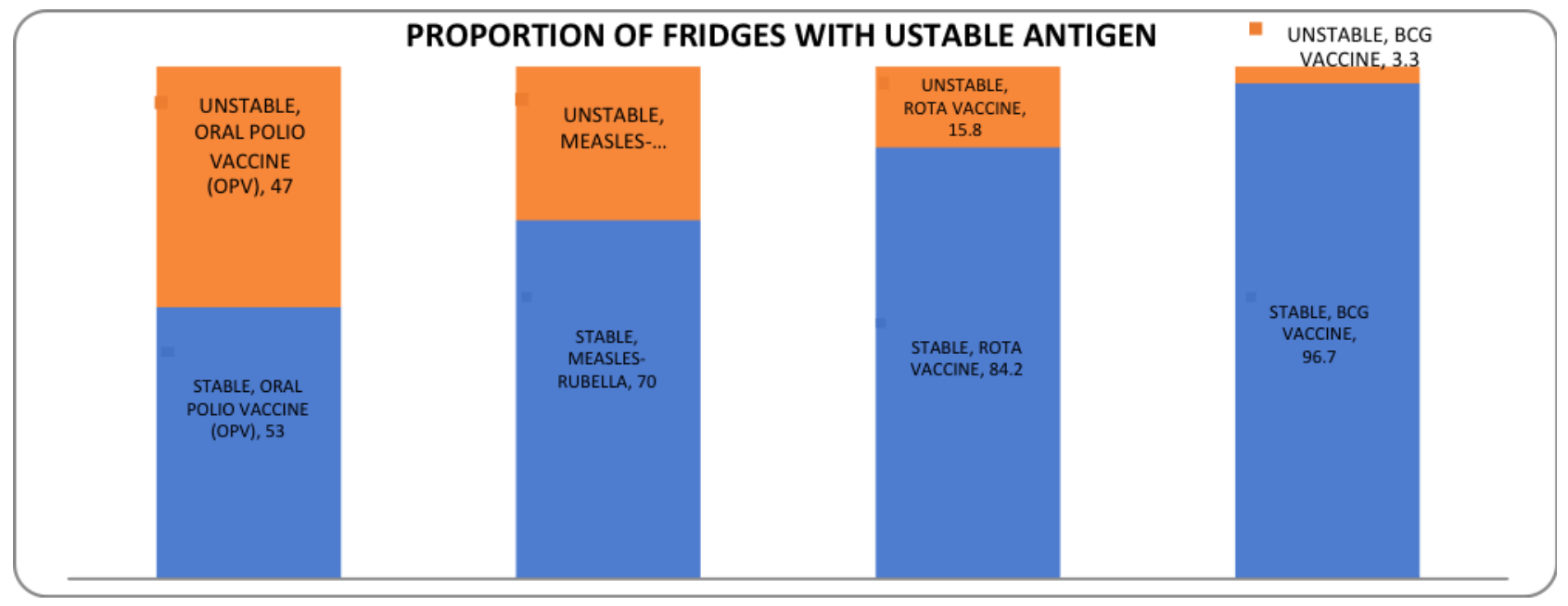

Fig. 2: Bar Graphs Showing Proportion Of Fridges versus Stability Status of Each Antigen

\section{DISCUSSION}

Though vaccines arrangements in the fridges were well observed in $67.5 \%$ of health facilities, OPV was still affected. It is possible that often, staff depict (stage-manage) ideal situations mainly during routine supervision to camouflage non-adherence. Evidence of food stuff and additional non-EPI drugs attests to non-adherence to guidelines. This might explain the observed OPV instability as frequent fridge opening precipitates internal temperature fluctuations. Similar lapses have been observed in other LMICs. Koskei et al., (2017) observed 50\% in a similar study in Kenya which compares closely 
to a study by Rogie, et al., (2013) who observed $45.5 \%$ adherence level to vaccines arrangement in Ethiopia. Both Rogie and Kosgei however, did not consider impact of these on the vaccine instability. Krishnappa et al., (2014) established $36.4 \%$ adherence to vaccines arrangement order while they were evaluating cold-chain practices in urban health centers of a metro city in India.

Using VVM staging to dispense vaccines is a new technological approach of reducing vaccine wastage but seems to not be adequately observed by most staff. As shown in the study, $45.8 \%$ of facilities did not issue vaccines at VVM stage 2 instead they randomly dispensed, leading to a significant influence on all live-attenuated antigens in the study except BCG vaccine.

Based on VVM staging, it is worth appreciating that despite the fact that defrosting of fridges might have been a lesser concern in this County following the new supply of fridges, the $12.5 \%$ facilities which did not defrost had a significant adverse effect on the stability of all live attenuate vaccines except BCG. This implies vaccines spent more times outside the recommended range in freezing zones. It is possible that in this region uncertainties associated with erratic power supplies, lack of power back-up as well as wide climatic temperature ranges between $22^{\circ} \mathrm{C}$ to $36^{\circ} \mathrm{C}$ in a day precipitates poor fridge temperature regulation (Okomo et al., 2019). While these challenges by themselves call for strict adherence to guidelines for the sake of sustaining vaccines' stability, the current study findings show considerable lapse in adherence with regard to vaccine arrangement, transfer vaccines and, defrosting fridges to ensure optimal temperature regulation. There is need to reconsider the current approach to conducting support supervision for immunization service providers at peripheral facilities. Remote temperature monitoring tool is an innovative digital technology that would help managers in prompting recurrent lapses to address them, for example through staff behavior change and competency based refresher cold chain management skills.

\section{CONCLUSION}

There are gaps in adherence to cold-chain system guidelines at health facility levels, such as failures to: transfer vaccines to safer fridges; defrosting of fridges and use of VVM staging to dispense vaccines a head of FEFO sequence. All had significant influence on the stability of ROTA, OPV and measlesrubella vaccines but not BCG. Placement of food stuff and non EPI drugs worsened the situation. It is justifiable to link these with the occasional resurgence of Rota diarrhea and measles diseases in Kisumu County.

\section{Recommendations}

- There is a need for a strengthened focused support, supervision to health facility staff by senior stakeholders in cold-chain management to improve adherence level to the guidelines

- There is a need for regular sensitization and updates to service providers on quality cold-chain management.

- Provision of additional fridges to every health facility that offers immunization is encouraged to cater for non EPI essential drugs which also require cold storage

- It is a rational idea to recommend fridges with ability freeze ice-packs for Kisumu County rather than the new non-freezing fridges in respect to warm climatic status in the region 


\section{Declarations}

\section{Ethics Approval}

Ethical clearance was obtained from Maseno University Ethics Review Committee (Ref: MSU/DRPI/MUERC/00625/18). Consent and administrative approval was also obtained from the Kisumu County Director of heath. (Ref: CGK/DH/GN/133/VOLIII/ (232)/18; Medical officers in charge of each of the six Sub Counties and respective in charges / respondents in each health facility sampled.

\section{Abbreviations}

BCG: Bacilli Calmette-Guérin, EG: Electric Grid, EPI: Expanded Program on Immunization, FB: Faith Based, GOK: Government of Kenya, KEPI: Kenya Expanded Program on Immunization, MOH: Ministry of Health OPV; Oral Polio Vaccine, PR: Private, S/CHMT: Sub County Health Management Team, T.T: Tetanus Toxoid vaccine, VVM: Vaccine Vial Monitor, W.H.O: World Health Organization

\section{Competing interests}

The authors declare that they have no competing interests.

\section{Authors' contributions}

MOOJ conceived, designed, coordinated and performed the study. MOOJ, DOA and BG analyzed the data. MOOJ and DOA drafted the manuscript. All authors read and approved the final manuscript.

\section{Disclaimer}

The findings and conclusions presented in this manuscript are those of the authors and do not necessarily reflect the official position of Maseno University

\section{Acknowledgements}

We are grateful to all who directly and indirectly participated in this study specifically, the health staff from facilities, including managers, the Director of health services Kisumu County and all enumerators.

\section{Data Sharing}

Requests for the data used for this analysis may be made to lead author, Moses Olunga Okomo John, jomokomo2010@yahoo.com, and can be shared

\section{Funding}

This was a self-sponsored by the lead author, who is a PhD student at Maseno University 


\section{REFERENCE}

- Angela K. S., Rebecca F., and Mike M (Glob Health SciPract. 2014 Dec; 2(4): 381-394. Published online 2014 Dec 2. doi: 10.9745/GHSP-D-14-00137)The future of routine immunization in the developing world: challenges and opportunities

- Cambridge (2013) Advance Learners' English Dictionary $4^{\text {th }}$ Edition Cambridge University Press

- District Health Information System (“DHIS" 2014; 2015; and 2016) Kenya.URL

- Gliem, J.A and Gliem R.R. (2003) Calculating, Interpreting, and Reporting Cronbach's Alpha Reliability Coefficient for Likert-Type Scales. Continuing, and Community Education, Columbus, 82-88.

- Israel, Glenn D. (2009). Sampling the Evidence of Extension Program Impact. Program

- Evaluation and Organizational Development, IFAS, University of Florida. PEOD-5. October.

- Karl Pearson (1895) "Notes on regression and inheritance in the case of two parents,"

- Proceedings of the Royal Society of London, 58: 240-242.

- Koskei, A., Mibei, E., Tabu, S., Malalu, P., Marete, I., \& Tenge, C. (2017). Assessment of cold chain management practices in immunisation centres in Kacheliba division, Pokot County, Kenya. East African Medical Journal, 94(2), 106-110. Mercy lutukai et al.,

- Lutukai, M., Bunde E. A., Hatch, B., Zoya, M., Yavari, S. E., (2019) Global Health: Science and Practice, 7(4):585-597; URL

- Ministry of Health (2012) EPI operational level manual for service providers. Gvt. printers. KENYA

- Mugenda, A. G., (Olive) (2003), Research Methods: Quantitative and Qualitative Approaches. Nairobi. Kenya .Acts Press.

- Ministry of Public Health and Sanitation (2013) Measles vaccine second dose introduction in routine immunization. Guide for health workers. Government Printers. Kenya

- Okomo, O.M.J., Guya .B., Omondi, D.S.A, (2019) Facility Level Cold-Chain Maintenance, Temperature-Monitoring and Stability of Live Attenuated Vaccines in Kisumu County, Western Kenya. IJIRDI.

- Ram K. Panika., Amarnath Gupta (2018) Assessment of cold chain and logistics management practices: a cross sectional study in Bundelk-hand region of Madhya Pradesh: International journal of Community Medicine and Public Health. URL

- Rogie, B., Berhane, Y., Bisrat, F (2013) Assessment of cold chain status for immunization in central Ethiopia.Addis Continental Institute of Public Health, Addis Ababa, Ethiopia.

- Shen A. K., Fields R., McQuestion M (2014) the future of routine immunization in the developing world: challenges and opportunities. Glob Health Sci. Pact. 2014; 2(4):381-394. URL 
- World Health Organization (2006). Temperature sensitivity of vaccines. Geneva, Switzerland at URL.

- World Health Organization (2015a) Guidelines on the stability evaluation of vaccines for use under extended controlled temperature conditions. Geneva, Switzerland

- World Health Organization,(2015b). Africa's health monitor. Routine immunization in the WHO African Region: Progress, challenges and way forward: Joseph Okeibunor, e-mail: okeibunorj@who.int

- Yamane, Taro (1967). Statistics, An Introductory Analysis, 2nd Ed., New York: Harper and Row. 